\title{
Repurposing Cathodic Protection Systems as Reliable, in-situ, Ambient Batteries for Sensor Networks
}

\author{
Anonymous Author(s)
}

\begin{abstract}
The majority of infrastructure is susceptible to, and therefore must constantly combat, corrosion. The monitoring and maintenance of corrosion protection (or the consequences of its unchecked failure) is often one of the leading costs of infrastructure upkeep. Galvanic cathodic protection is a common corrosion control technique that is employed in applications from home appliances to boats to bridges. At its core, however, galvanic cathodic protection is simply an electrochemical cell-that is, a battery. This presents an opportunity to treat this corrosion protection as an in-situ power source that by definition will last as long as the protection system itself. In this paper, we explore the efficacy of these pervasive, "ambient galvanic cells" as potential energy harvesting sources. We then show how to use these cells as a power source for wireless sensing devices that monitor the health of the same corrosion protection system. Our system takes advantage of newly available LPWAN technologies that allow for effortless wide-area coverage. We demonstrate the viability and efficacy of the system on one of the most common galvanic cathodic protection systems, home hot water heaters. We show that this technique can be a powerful new asset for corrosion monitoring and for deploying wireless sensor networks broadly.
\end{abstract}

\section{CCS CONCEPTS}

- Computer systems organization $\rightarrow$ Embedded and cyberphysical systems; $\bullet$ Hardware $\rightarrow$ Energy generation and storage; $\bullet$ Applied computing $\rightarrow$ Physical sciences and engineering.

\section{KEYWORDS}

Ambient Galvanic Cell, Ambient Battery, Corrosion, Energy Harvesting, Cathodic Protection, Deterministic Intermittent Computing

\section{ACM Reference Format:}

Anonymous Author(s). 2020. Repurposing Cathodic Protection Systems as Reliable, in-situ, Ambient Batteries for Sensor Networks. In Proceedings of The 20th International Conference on Information Processing in Sensor Networks (IPSN'21). ACM, New York, NY, USA, 12 pages.

\section{INTRODUCTION}

Corrosion is a natural process that continually takes place all around us. It affects nearly all refined metals. As a result, infrastructure maintenance in the face of corrosion is one of the more challenging and costly aspects of the modern built world. In a landmark study released in 2002, "the total annual estimated direct cost of corrosion

Permission to make digital or hard copies of part or all of this work for personal or classroom use is granted without fee provided that copies are not made or distributed for profit or commercial advantage and that copies bear this notice and the full citation on the first page. Copyrights for third-party components of this work must be honored.

For all other uses, contact the owner/author(s).

IPSN'21, May 18-21, Nashville, TN, USA

(c) 2020 Copyright held by the owner/author(s)

ACM ISBN 978-x-xxxx-xxxx-x/YY/MM.

DOI: $10.1145 / 3412382.3458277$ in the U.S. is a staggering $\$ 276$ billion-approximately $3.1 \%$ of the nation's Gross Domestic Product (GDP)" [22]. A report in 2009 estimates the global cost of corrosion to be around \$1.8 trillion (USD) annually [32]. Failure to properly address corrosion can result in premature ageing of infrastructure, which requires costly replacement $[27,36]$. Extended absence of prevention and maintenance has severe consequences, with $25 \%$ of "significant incidents" in United States pipelines and $50 \%$ of ruptures in Canadian pipelines being attributed to corrosion over a 20 year period [13].

There are five techniques to reduce corrosion: material selection, environmental modification, corrosion inhibitors, coatings, and cathodic protection. Ideally, multiple techniques are used in tandem to form a complete corrosion control system [12]. In this paper, we focus on cathodic protection as it is often the 'last line of defense' in corrosion control. Generally, if cathodic protection is relied on for corrosion defense, when that protection fails, corrosion will occur.

Corrosion is the slow wearing away or weakinging of a structure. In refined metals, it takes place when the metal spontaneously gives up electrons. Cathodic protection prevents this by supplying excess electrons to the metal, which stops the metal from ionizing, thus preventing its corrosion [31]. As the metal is receiving electrons, it is considered a cathode, hence, cathodic protection.

Galvanic cathodic protection is one of the two primary cathodic protection techniques (the other is impressed current, discussed in Section 7.3). Galvanic protection sees frequent application as it is very simple to deploy and completely passive. First invented in 1833 to prevent corrosion for the British Navy [6]-and still used on nearly every boat today-, galvanic cathodic protection exploits the galvanic corrosion of a sacrificial metal to protect the primary structure. When two dissimilar metals are connected via an electrolyte (such as water), one will donate electrons to the other; this chemical process is known as galvanic corrosion. The metal that is donating electrons is therefore undergoing two corrosion processes: ambient chemical corrosion with its environment and galvanic corrosion. Ideally, the metal which is receiving electrons will exhibit no corrosion, as the supply of electrons from galvanic corrosion suppresses its environmental corrosion. One metal sacrificing itself to protect another is the essence of galvanic cathodic protection.

Interestingly, however, 'two dissimilar metals connected via an electrolyte' is also a definition of an electrochemical cell, or more simply, a battery. ${ }^{1}$ In this paper, we propose using the "ambient galvanic cells" formed by corrosion and corrosion prevention systems as semi-ubiquitous power sources for infrastructure monitoring applications. We will show that with power-banking techniques from energy harvesting systems there is ample energy to support environmental monitoring systems. As a first use case, we look to one of the more pervasively deployed galvanic cathodic protection systems: hot water heaters. We introduce the design of a system

${ }^{1}$ Indeed, the first electrical battery, made by Alessandro Volta in 1799, was the voltaic pile, which was made up of repeated layers of zinc and copper in brine. 
that both powers itself off the protection system and monitors and reports the health of the galvanic cell itself, which is effectively a report of the health of the cathodic protection system.

Proper corrosion protection can double or triple the lifetime of a home hot water tank. This can yield significant savings as replacing a residential hot water tank costs around $\$ 1,200$ USD, while a sacrificial anode rod costs just \$20 USD. Capturing this benefit, however, relies on homeowners replacing sacrificial anodes when they expire. This can be challenging, as the anode consumption rate varies non-linearly with water use, temperature, salinity, and total dissolved solids [30]. As there are not corrosion control engineers evaluating anode lifetimes for each home, estimates of anode lifetime vary wildly. An informal survey of plumbing guidelines finds that they usually suggest a lifetime of 3-5 years but some suggest as little as 1 year and others as many as 10 years. This long lifetime-and wide range-is emblematic of corrosion control.

This is not just a homeowner maintenance problem. In practice, the cost and overhead of monitoring and upkeep for cathodic protection can result in its (eventual) omission from the corrosion control strategies of significant pieces of infrastructure. A 2009 report on concrete bridge maintenance found that of 24 municipalities with at least one cathodic protection system installed, ${ }^{2}$ only 10 monitor any and only 5 monitor all of their systems [35]. ${ }^{3}$ This is despite National Association of Corrosion Engineers (NACE) recommendation [28], and state and federal requirements [8, 34, 36, 37], that cathodic protection systems be inspected 30 days after changes to the infrastructure or environment and every 1 to 3 years otherwise.

For a potential monitoring solution, the challenge is that the use of traditional battery-backed sensors simply trades one maintenance problem for another. If batteries demand replacement on a similar schedule as prior corrosion monitoring inspections, then sensors will have made the maintenance burden no better. This motivates a battery-free, and thus maintenance-free, energy harvesting approach to corrosion control monitoring. Furthermore, while sunlight, thermal gradients, or other traditional energy scavenging opportunities may be available at any one corrosion control site, finding a means to draw system power from the corrosion control itself holds appeal as it is an energy source that is certain to be available in all cathodic protection settings.

Galvanic cathodic protection systems cannot directly replace a traditional power supply, however. They provide a few hundred millivolts to a volt and maybe tens of milliamps. This is actually far more power than the supply of many recent energy harvesting systems, however [17, 23, 24]. As power supplies, these cells further have the battery-like properties of stable and always-available energy capacity (on electronics timeframes). This is the first key observation and contribution of this paper: for many infrastructure monitoring applications, the batteries are already included.

These ambient galvanic cell "batteries" are doubly interesting as they solve one of the most challenging problems for real-world

\footnotetext{
${ }^{2}$ These are a mixture of impressed current and galvanic systems for cathodic protection One suggestion explored in the report was a transition from active, impressed current protection to passive galvanic systems. However, several municipalities indicated that even such passive systems are too challenging to monitor and maintain.

${ }^{3}$ E.g., "Texas does not believe it can monitor and maintain the [cathodic protection] systems and therefore does not use them. Utah had a total of seven systems, all of which failed because they were not able to monitor and maintain them." [35, Chapter 5]
}

deployments on infrastructure: lifetime. Galvanic cathodic protection in particular has a remarkable lifetime property. The efficacy of the protection is defined by the voltage of the galvanic cell. This means that by definition if a galvanic cathodic protection system is working, it will be able to supply power to a monitoring system.

This paper envisions a future with embedded corrosion monitoring systems powered from the corrosion protection itself. Such a system is self-contained, imposes no additional maintenance burden, and is able to proactively detect premature failure of corrosion control. We wish to note up front that a single point measure of large system may not be sufficient to validate that an entire structure is protected. It is, however, sufficient to detect when it is not protected. Thus, for this first exploration into autonomous monitoring of corrosion control, our goal is to detect and report premature failure of protection systems before corrosion sets in.

In summary, this paper makes the following contributions:

- We introduce the concept of the ambient galvanic cell, a widely available energy source in the built environment.

- We characterize the performance of one specific and common ambient galvanic cell, the home hot water heater.

- We show how the stability of ambient galvanic cells (in contrast to less predictable sources like RF and solar) enable a new execution model for energy harvesting systems that we term dependable intermittent operation.

- We implement and evaluate an end-to-end system which demonstrates the viability and efficacy of a self-powered cathodic protection monitoring system.

We close with a discussion of the larger vision for ambient galvanic cells. Cathodic protection is surprisingly ubiquitous, and as a result, there are decades-long "batteries" already deployed throughout the built environment - we simply need to plug into them! In this paper, we explore using the energy from these batteries to monitor the energy source itself, however, it could just as easily be used to power any other sensor or application (albeit at limited, inflexible duty cycles). As stable trickle sources, ambient galvanic cells can also augment more traditional, higher-power harvesting sources to provide a consistent baseline and to prevent the total power loss that often complicates intermittent designs. We view ambient galvanic cells as a key facet to addressing the deployability challenge for wide-area, long-lived sensor networking applications.

\section{THE CHEMISTRY OF CORROSION}

We start with an overview on the principles of corrosion and galvanic reactions. The goal is to provide background on how ambient galvanic cells operate, where they might be found, and their potential as a general energy scavenging source.

\subsection{Corrosion}

Chemically speaking, most refined metals are in a higher energy state than their naturally occurring ores. Conceptually, ambient galvanic cell "batteries" are "charged" during the refining process. Corrosion is the process that returns metals to their natural oxidation states (e.g. naturally occurring ores). This reduction in energy potential is why corrosion occurs spontaneously. 
In the presence of an oxidant (e.g. oxygen in the air or dissolved in water), most metals will self-corrode to some degree. As a simple example, if magnesium is placed in water it will corrode to magnesium oxide and form hydrogen gas as a byproduct:

$$
\mathrm{Mg}_{(\mathrm{s})}+2 \mathrm{H}_{2} \mathrm{O} \longrightarrow \mathrm{Mg}(\mathrm{OH})_{2(\mathrm{~s})}+\mathrm{H}_{2}(\mathrm{~g})
$$

this corrosion reaction can be broken down into anodic Eq. (2), cathodic Eq. (3), and product formation Eq. (4) reactions: ${ }^{4}$

$$
\begin{aligned}
\mathrm{Mg}_{(\mathrm{s})} & \longrightarrow \mathrm{Mg}_{(\mathrm{aq})}^{2+}+2 \mathrm{e}^{-} \\
2 \mathrm{H}_{2} \mathrm{O}+2 \mathrm{e}^{-} & \longrightarrow \mathrm{H}_{2}(\mathrm{~g})+2 \mathrm{OH}^{-} \\
\mathrm{Mg}_{(\mathrm{aq})}^{2+}+2 \mathrm{OH}^{-} & \longrightarrow \mathrm{Mg}(\mathrm{OH})_{2(\mathrm{~s})}
\end{aligned}
$$

Figure $1 \mathrm{~b}$ shows the impact of corrosion on a magnesium rod.

\subsection{Galvanic Corrosion}

If two metals are electrically connected, they may undergo galvanic corrosion, which accelerates the overall corrosion of one metal (the anode) while halting the corrosion of the other metal (the cathode) This is the principle that underlies galvanic cathodic protection. A second, sacrificial metal is introduced to undergo galvanic corrosion and halt the normal corrosion of the protected metal.

Whether two metals will undergo galvanic corrosion is determined by their relative position in a galvanic series. A galvanic series measures the inherent electrode potentials of metals or metal alloys in a given electrolyte. This difference of electrode potentials between the two metals drives the corrosion reaction. The metal which has a more electronegative potential-the anode-loses electrons and undergoes oxidation while the metal which has a more electropositive potential-the cathode-gains electrons and undergoes reduction simultaneously. With tap water as the electrolyte, magnesium is near the bottom of the galvanic series. This makes magnesium an excellent sacrificial anode material, as it will protect most other metals (magnesium is also prevalent in nature and cheap to produce, which is why it is often used in practice).

Normally, if steel is wet and exposed to air, it will corrode $\left(\right.$ rust $\left.^{5}\right)$ :

$$
\begin{aligned}
\mathrm{Fe}_{(\mathrm{s})} & \longrightarrow \mathrm{Fe}_{2}{ }^{+}{ }_{(\mathrm{aq})}+2 \mathrm{e}^{-} \\
\mathrm{Fe}_{2}{ }^{+}{ }_{(\mathrm{aq})}+2 \mathrm{OH}^{-} & \longrightarrow \mathrm{Fe}(\mathrm{OH})_{2}(\mathrm{~s})\left[\frac{\text { Iron(II) hydroxide }}{\text { a white powder }}\right] \\
4 \mathrm{Fe}(\mathrm{OH})_{2(\mathrm{~s})}+\mathrm{O}_{2}+2 \mathrm{H}_{2} \mathrm{O} & \longrightarrow \mathrm{FeO}(\mathrm{OH}) \mathrm{H}_{2} \mathrm{O}_{(\mathrm{s})\left[\frac{\text { Iron(III)hydroxide }}{\text { yellow rust }}\right]}
\end{aligned}
$$

However, if there is ample magnesium present then the anodic rust reaction Eq. (5) will be suppressed in favor of the anodic magnesium corrosion reaction Eq. (2). The anodic rust reaction Eq. (5) is effectively driven backwards (becoming cathodic) by the electrons from the anodic magnesium reaction Eq. (2). Critically, this protection will only occur if the iron and magnesium are electrically well-connected. As seen in Fig. 1c, galvanic corrosion will accelerate the natural corrosion of the sacrificial metal. The question of which anodic reaction will dominate is the essence of a galvanic series, the details of which are beyond the scope of this paper.

\footnotetext{
${ }^{4}$ Corrosion reactions are redox reactions and are to varying degrees both chemically and electrochemically reversible. For simplicty of exposition, we present them all as simple forward reactions, which show the primary corrosion pathway.

${ }^{5}$ Shown here is one of the simplest rust formation processes. In practice, there are multiple rusting pathways, usually occurring in parallel, which depend on the local macro and micro environment around corrosion sites. Most corrosion has multiple pathways, but they share the initial electron loss as the first step, which is why cathodic protection is effective as a broad-based corrosion prevention technique.
}
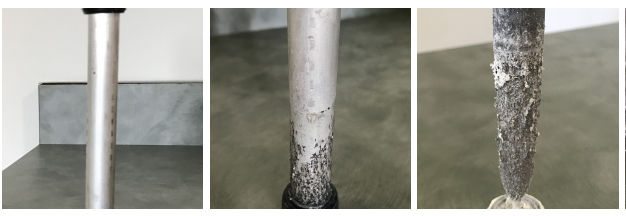

(a) New anode. (b) With plastic. (c) With metal.

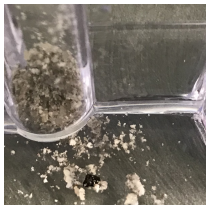

(d) Precipitate.

Figure 1: Examples of Corrosion. This is an example of a magnesium rod before (a) and after (b), (c) exposure to a corrosive environment. In (b), the rod is placed in a plastic bucket full of tap water, which results in only mild corrosion. In (c), the rod is placed in a metal bucket full of tap water, in which case it undergoes galvanic corrosion with the bucket. The "lost" material from the magnesium rod primarily becomes flakes of magnesium oxide, as seen in (d). Notice that the corrosion does not take place evenly over the surface. Due to a variety of factors (impurities, grain size, ambient salts, etc.), corrosion often occurs by "pitting." These pits can extend deep into the metal and sideways beneath the surface, which makes accurate estimation of damage once corrosion occurs challenging [4]. This is why seemingly modest corrosion can in some cases lead to critical failures and why it is important to prevent corrosion before it begins as much as possible.

\subsection{Designing a Cathodic Protection System}

To prevent corrosion of a protected metal, "enough" electrons must be present to reverse the oxidation reaction. The rate of corrosion, and thus the amount of cathodic protection required, is a function of the types of metals in the system, the environment, and the exposed surface area of the metal being protected. To help with design, NACE provides guidelines for the cathodic potential that must be present between the structure to be protected and the anode. As an example to get a sense of the numbers for such a system, in a noncoastal (not salty), temperate $\left(7-12^{\circ} \mathrm{C}\right)$ climate a magnesium anode protecting bare steel requires $0.1 \mathrm{~A} / \mathrm{m}^{2}$ of cathodic current to prevent corrosion in steady state conditions [9]. A $1 \mathrm{~kg}$ block of magnesium $\left(575 \mathrm{~cm}^{3}\right)$ can provide approximately $1,110 \mathrm{Ah}$ of effective cathodic protection. If one square meter of bare steel is exposed, this cathodic protection will last for about 15 months. This rapid consumption of sacrificial anodes is why corrosion control systems work in tandem. The primary protection is usually a coating that aims to limit the exposed surface area. Cathodic protection shields against corrosion from imperfections in the coating and damage over time.

\subsection{Monitoring Galvanic Cathodic Protection}

Cathodic protection fails when the sacrificial anode no longer prevents the spontaneous oxidation of the protected metal. If the anode becomes electrically disconnected, protection stops immediately. As the anode deteriorates, its ability to donate electrons falters, and the primary corrosion reaction will begin to progress slowly. This degradation of anode capability manifests as a reduction of the effective electromotive force (EMF).

The EMF of an electrochemical cell describes the open-circuit potential difference between the anode and cathode. In lab conditions, EMF is fixed as it is set by the energy change in the underlying chemical reaction (the Gibbs energy). In real-world conditions, 
conductivity of the electrolyte, effective electrode surface area, electrode geometry, temperature, turbulence in the electrolyte, and myriad other factors affect the underlying reaction and thus the effective EMF. Recall however that this underlying reaction is the cathodic protection reaction. Thus, if the measured EMF dips low for any of the many possible reasons, the cathodic protection is failing, and a monitoring system should alert the condition.

In addition to EMF, a monitoring system might also attempt to estimate the short-circuit current available in the cell. Current is largely controlled by the available reaction sites (surface area) and rate of reaction (environmental conditions). Thus, measuring current may allow a sense of the rate of consumption of the cathodic protection system, but a change in current does not necessarily indicate a change in the underlying corrosion of the protected metal Indeed, when coatings are still intact, there are minimal reaction sites available on the protected metal, which means minimal current. Assuming there is any imperfection in the coating, however, the EMF will still be at the expected value. When a sacrificial anode fails due to consumption, both the current and the effective EMF will fall. Because current can vary in ways unrelated to protection, we focus our design on the effective measure of EMF.

\section{EXPLORING CORROSIVE CELLS}

Our chemistry of corrosion presents a simplified view of the world which looks only at the desired reactions. The real world, however, has many other interactions going on at the same time which may interfere with our desired energy capture ideas. Further, unlike traditional batteries, the chemistry that underlies an ambient galvanic cell has not been optimized for power delivery, which may limit the ability to run electronics directly from an ambient galvanic cell.

To begin, we build a simple corrosive cell with minimal confounds to verify that there is sufficient energy available upon which to build a system. Then we consider the various factors which may affect an eventual hot water tank based design-the relative anode rod to tank surface area, the age of the anode rod, and the salinity, $\mathrm{pH}$, and temperature of the water electrolyte-to understand what factors affect the energy delivery capacity of the cell and to thus ensure that there will be sufficient energy available to power a monitoring system across the variety of hot water tank setups.

\subsection{Can We Get Energy From a Vat of Water?}

In Fig. 2, we show a simple corrosive cell. We choose to use a stainless steel bucket for initial experimentation because unlike plain steel, it will not easily rust or change properties over the course of experiments. It will, however, still act as a cathodic electrode and allow us access to the potential from the degrading magnesium rod. It is actually fairly common to introduce cathodic protection to metals that "do not corrode" such as stainless or galvanized steel as part of a defense-in-depth strategy against real-world corrosion.

We should be able to predict the approximate performance of a generic bucket-of-water battery. Using a galvanic series for tap water [26], everyday stainless steel ${ }^{6}$ has a standard potential of $-0.05 \mathrm{~V}$, while magnesium is $-1.3 \mathrm{~V}$. As a quick point of emphasis

\footnotetext{
${ }^{6}$ Consumer-grade products rarely specify their exact composition. As a low-cost, general purpose bin, it is most likely Type 410, or possibly Type 304 or Type 430 , stainless steel. As these alloys are all within a few tens of millivolts in standard potential, the exact metal is unimportant for this analysis.
}

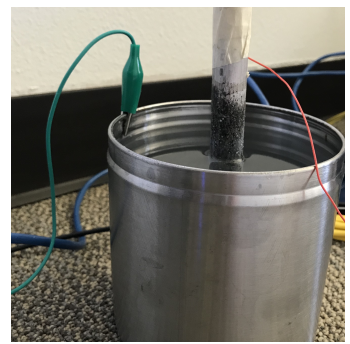

Figure 2: A Corrosive Cell. A magnesium rod (anode) in a stainless steel bin (cathode) filled with tap water (electrolyte) forms an electrochemical cell, driven by the corrosion of the magnesium rod.

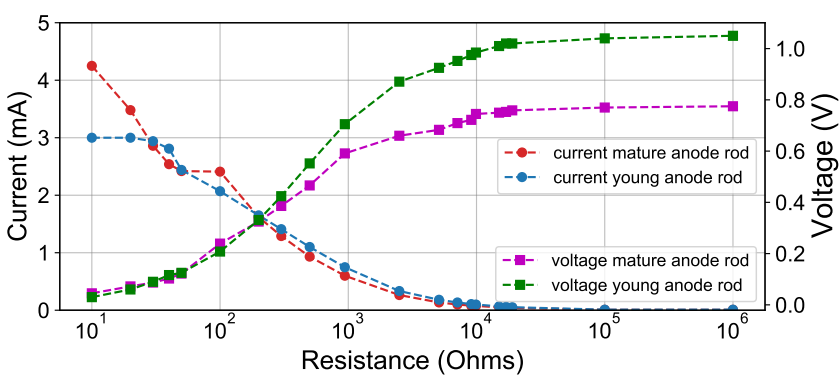

Figure 3: Power Delivery Potential. We place a magnesium rod in a stainless steel bin filled with tap water. We then connect a series of resistors from $10 \Omega$ to $1 \mathrm{M} \Omega$ between the rod and the bin. At each step, we capture the current and voltage available from the ambient galvanic cell. The cell takes several seconds for output to stabilize at each new impedance. We consider the output as stable once it changes no more than $1 \mathrm{mV} / \mathrm{s}$. Peak power for this cell is around $0.64 \mathrm{~mW}$, ample supply for an energy harvesting system.

on the significance of the electrolyte, we note that a galvanic series for the same metals in sea water [3] expects $-0.5 \mathrm{~V}$ for steel and $-1.6 \mathrm{~V}$ for magnesium. As a very first test then, we simply measure the open circuit voltage of this cell. After some time, we find that the potential stabilizes to $1.2 \mathrm{~V}$, which confirms that the basic operation of the cell is working as we expect.

\subsection{What Affects Available Energy?}

We are now interested in understanding how close-or how far-a corrosion cell is from a traditional battery. This section explores the baseline instantaneous power available from the cell as well as the factors that affect the energy delivery capacity of the cell.

3.2.1 Nominal Performance. To understand the baseline performance, we perform an impedance sweep of our cell with tap water at room temperature. The results are shown in Fig. 3. At low impedances, the limited reaction rate of corrosion cannot maintain the output voltage. Peak power for the cell occurs at around half of the open circuit voltage at $550 \mathrm{mV}$. With $1.10 \mathrm{~mA}$ of current, $0.6 \mathrm{~mW}$ is ample power for an energy harvesting system. However, at only a few hundred millivolts, this maximum power point is fairly low, and may restrict the selection of harvesting frontends. 


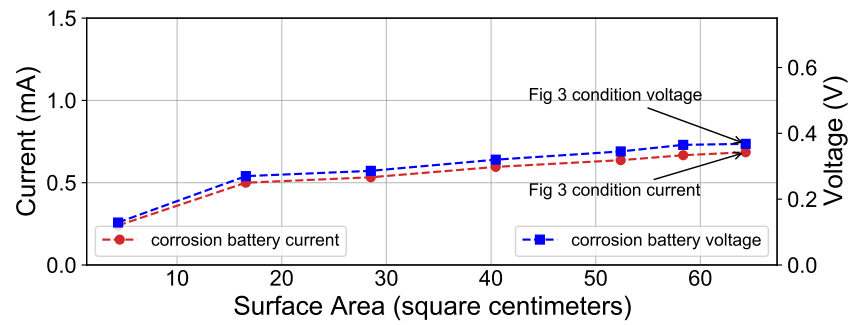

Figure 4: Anode Surface Area. We vary the effective surface area by progressively immersing more of the anode rod into the water. At each step, we measure the current of the cell across a $10 \mathrm{ohm}$ load. The surface area of the bucket in contact with the electrolyte is $460 \mathrm{~cm}^{2}$, thus the ratio of anode area to cathode area over the range of this experiment is $0-0.14$.

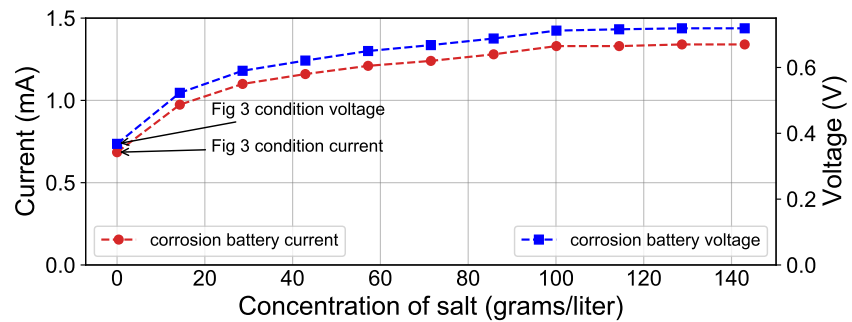

Figure 5: Electrolyte Salinity. Cell performance depends on the charge carrying capacity of the electrolyte. With no salts in the water, the electrolyte must rely on ions dissolved from the magnesium rod to act as charge carriers. Cell performance increases with salt concentration, until it is no longer the charge carrying capacity of the electrolyte that limits the reaction.

3.2.2 Anode Maturity. Figure 3 also considers both a "mature" and "fresh" anode rod. The first few hours or days of service tend to look very different from the long-term operation. This is because all of the elements of corrosion reactions take some time to reach equilibrium. This instability stems from significant changes in effective surface area-e.g. due to film formation from unrelated reactions or rapid consumption of microscopic roughness from manufacturingas well as concentration buildup in the electrolyte and rebalancing of charges with the greater environment. This phenomenon means that monitoring systems must be cognizant of major events such as anode replacement and must wait for the system to return to steady state operation before reporting on corrosion performance. We use a fixed $660 \Omega$ load, the maximum power point for the nominal cell, for the rest of the experiments presented in this section.

3.2.3 Surface Area. When designing galvanic cathodic protection systems, one of the key considerations is the relative surface area between the anode and the cathode. The surface area is important as the underlying chemical reaction occurs at physical sites on the metal, which means that the available surface area affects the rate of reaction. If a cathode is too much larger than a sacrificial anode, the protection reaction will not be able to keep up. In Fig. 4, we look at how surface area affects corrosion current. As expected, current grows linearly with the surface area in contact with the electrolyte.

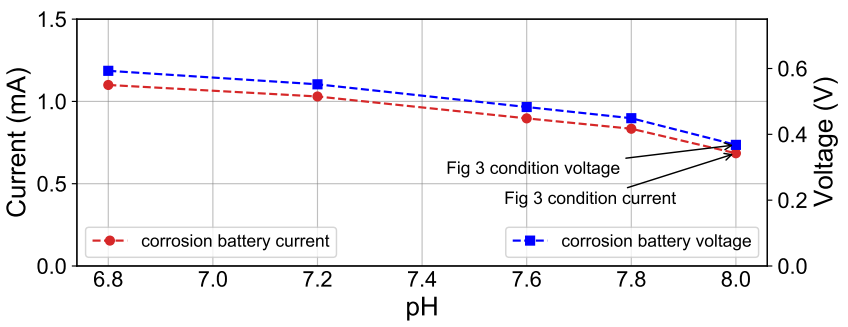

Figure 6: Electrolyte $\mathbf{p H}$. The $\mathrm{pH}$ of an electrolyte indicates the number of free hydrogen ions present in a solution. We vary the $\mathrm{pH}$ of the electrolyte starting with tap water. Initially the $\mathrm{pH}$ is 8 and is lowered subsequently by adding sodium sulphate. As $\mathrm{pH}$ drops, the corrosion current grows. Tap water, however, is normally slightly basic (to limit corrosion), which limits harvesting potential.

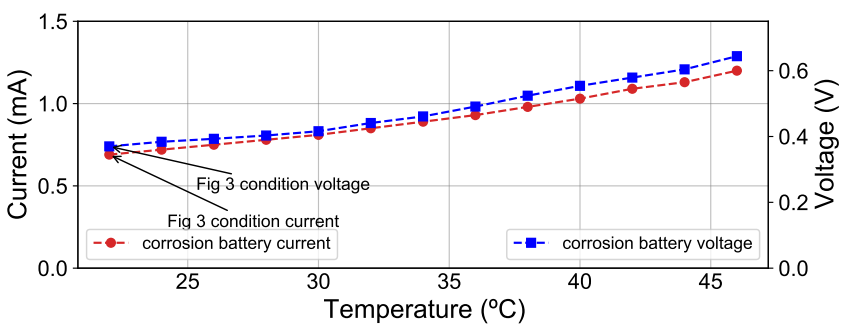

Figure 7: Electrolyte Temperature. We vary the temperature of the electrolyte by starting with hot tap water at around $46^{\circ} \mathrm{C}$. We sample periodically as the water cools. After it reaches room temperature we use an ice bath to cool it further and observe the trend. The available current increases with increase in temperature, but the rate of this increase slows with increasing temperature.

3.2.4 Salinity. For a corrosion cell to operate, the electrolyte must be able to carry a charge. The salinity of water strongly affects its charge carrying capacity. According to the local municipal water report [1], the sodium content of our tap water ranges from 0.06$0.09 \mathrm{~g} / \mathrm{L}$. As a reference point, ocean water generally has around $35 \mathrm{~g} / \mathrm{L}$ [38]. In Fig. 5, we begin with distilled water and slowly increase the salt content to see the impact on cell performance. As expected, with minimal salt content, the charge carrying capacity of the electrolyte limits the performance of the cell. Once the salt content exceeds roughly $40 \mathrm{~g} / \mathrm{L}$, the electrolyte is no longer the limiting factor, and additional salts do not significantly change behavior.

3.2.5 $\mathrm{pH}$. One challenge when experimenting with distilled water is that plain water is actually quite reactive. In open air, it will pull in carbon dioxide to form carbonic acid and shift from a neutral $\mathrm{pH}$ to about 5.8 in around two hours. In Section 2, we focused on corrosion in an akaline environment (the corrosion reactions involving $\mathrm{OH}^{-}$) because municipal tap water is generally slightly basic. Indeed, the municipal water quality report for our tap water reports an average $\mathrm{pH}$ of 8.04 (range 7.28-8.38). In Fig. 6, we look at the impact of $\mathrm{pH}$ on cell performance We observe that the corrosion current decreases as the $\mathrm{pH}$ of the electrolyte increases. Indeed, many municipal water supplies, including ours [1], alkalize water to lessen corrosion and extend the lifetime of city infrastructure [5]. 


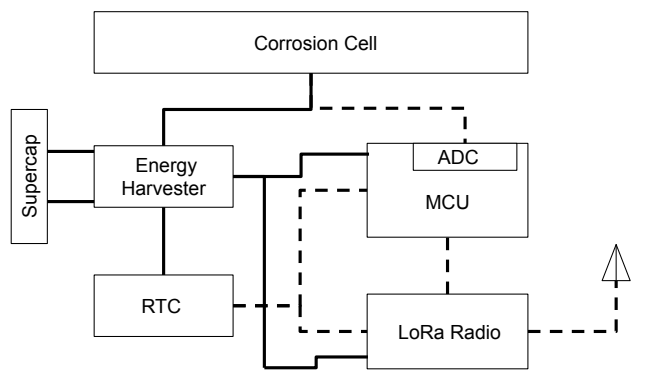

Figure 8: Block Schematic. Solid lines represent power signals while dashed lines represent control and data signals. The corrosion cell is connected to the Energy Harvester whose output powers the RTC, MCU and the LoRa Radio. The RTC sends the wake up signal to the MCU and LoRa Radio. The electrode potential is measured by the ADC and communicated to LoRa radio through $\mathrm{I}^{2} \mathrm{C}$. The measured value is transmitted by the radio to the LoRa network.

3.2.6 Temperature. Temperature affects both the conductivity of electrolytes and the rate of reaction for corrosion. Generally, conductivity of an electrolyte increases continuosly and superlinerarly with temperature. As seen in Fig. 7, however, in the corrosion cell, the effect of temperature increase wanes around $30-35^{\circ} \mathrm{C}$, as other factors begin to constrain the rate of corrosion.

\section{SENSOR DESIGN}

With a reliable energy harvesting source in hand, and an understanding of what we aim to measure, we turn to the sensor design. A galvanic cathodic protection sensor has three key pieces: (1) periodic wake-ups to trigger sense events, (2) a mechanism for sensing the health of the cathodic protection, and (3) a means of communicating the data. Our design will look at each of these in turn, and then we will use their energy requirements to drive the design of our energy storage and harvesting strategy. Figure 8 gives a high-level overview of the complete sensor design.

\subsection{Minimizing Energy Use}

Before beginning, it is worth noting that harvesting energy from a cathodic protection system can accelerate its degradation. A coarse estimate of the anode rod for our hot water tank suggests that it can provide around $210 \mathrm{Ah}$ of cathodic protection. At such scales, it is unlikely that a well-designed low-power electronics system will significantly impact the lifetime of the cathodic protection. ${ }^{7}$ Nonetheless, we aim to be mindful that energy spent powering the monitoring system is energy not spent suppressing the undesired corrosion reaction, and thus minimize energy use where sensible.

\subsection{Creating Periodic Wakeups}

The first design questions ask how often to sample and how to generate the sampling trigger. Corrosion and cathodic protection operate on very long time scales. Today's guidelines require that cathodic protection systems are inspected 30 days after installation or major changes (to verify they are working as intended after

${ }^{7}$ Concretely: $210 \mathrm{Ah} \times 1.1 \mathrm{~V}=831.6 \mathrm{~kJ}$. Our highest-energy configuration is $3.1 \mathrm{~J} /$ day. Over the 5 year expected protection lifetime, $5,678 \mathrm{~J}$ is less than $1 \%$ of the cell capacity.
Table 1: RTC Comparison. We survey an array of modern RTCs to understand the energy cost of timekeeping. State-of-the-art RTCs require extremely low power. Their energy use is on-par with simple passives while providing significantly more accuracy and reliability.

\begin{tabular}{l|cccc} 
RTC Model & Resolution $(\mathrm{ms})$ & Current $(\mathrm{nA})$ & Min V & Energy per 24h $(\mathrm{mJ})$ \\
\hline NXP PCF85263A & 10 & 320 & 3.3 & 91.2 \\
Maxim DS139X & 10 & 500 & 1.8 & 77.8 \\
ST M41T62 & 10 & 310 & 1.3 & 34.8 \\
Abracon AB18X5 & 10 & 51 & 1.8 & 14.3 \\
Ambiq AM08x5 & 8 & 14 & 1.5 & 1.8 \\
\hline \hline RC: $432 \mathrm{M} \Omega, 100 \mu \mathrm{F}$ & $\sim 30 \mathrm{~min}$ & N/A & N/A & 0.3 (at 2.4V)
\end{tabular}

environmental steady-state is well-established) and then annually after that. Coupled with other corrosion prevention and mitigation techniques, this inspection schedule is usually sufficient to protect against leaks or failures, but it is not necessarily frequent enough to catch corrosion before it sets in. As a result, these infrequent inspections can result in costly repairs or replacements. Proactively detecting cathodic protection failure motivates sampling more often than once a year, however, something like once a day is plenty.

For intermittent systems, the classic simple, low-power timing technique is an RC circuit [18]. At a system voltage of $2.4 \mathrm{~V}$ (which our radio will later require) an $\mathrm{RC}$ circuit will fall to around $0.3 \mathrm{~V}$, a reasonable logic-low threshold, in two time constants. To realize a 43,200 s time constant with an RC circuit one would need something like $432 \mathrm{M} \Omega$ and $100 \mu \mathrm{F}$ passives.

Such a timing circuit would be highly sensitive to environmental noise. Indeed, often-ignored factors such as gate-source leakage of MOSFETs or offset current of comparators become significant. Looking at the lower-leakage option, for today's small-signal, discrete FETs, gate-source leakage is around $0.01 \mathrm{nA}$ [29]. ${ }^{8}$ The initial $\mathrm{RC}$ discharge current is only $5.6 \mathrm{nA}$. Integrated, this leakage alone can account for $2 \%$ error, or nearly half an hour of drift over the course of a day. While this specific challenge could be addressed by lowering the resistance and increasing the capacitance beyond the already-large $100 \mu \mathrm{F}$ (whose leakage we have not yet discussed), we note that the discharge of just $100 \mu \mathrm{F}$ from $2.4 \mathrm{~V}$ to $0.3 \mathrm{~V}$ already requires around $0.3 \mu \mathrm{J}$. As we imagine reconfiguring passives for higher reliability, either through larger banks or in chains as suggested by Botoks [7], this energy use will grow, and we will lose both the purported simplicity and energy savings of a RC timer.

This motivates looking at more traditional timekeeping, namely RTCs. Table 1 surveys modern RTCs to understand how much energy would be required to use them as a daily wakeup source. Over the same $24 \mathrm{~h}$ period, an AM08x5 RTC requires only $1.8 \mathrm{~mJ}$. This is remarkably close in energy to the passives-only approach, and provides a far more stable and reliable time base. The takeaway here is that in contrast to traditional intermittent computing, which operates on timescales of seconds to minutes, once a system is looking at hours or days, it is very hard to beat the energy efficiency and reliability of modern RTCs. For these reasons, we choose an RTC as our periodic wakeup source.

Design Implication: Use of an RTC requires that the system can supply a constant, albeit small, power draw.

${ }^{8}$ Note that if the discrete includes ESD protection, the Zener will dominate this leakage, and it will be closer to $1 \mathrm{nA}$ [29]. 


\subsection{Sensing and Processing}

The next step is to sense the effective cell EMF. Our monitor will need to sample the potential difference between electrodes. Recall that the potential difference between the two electrodes is what drives the sacrificial corrosion process. Without the presence of that driving potential difference, there would be no protection process taking place. Thus the measure of effective EMF or potential difference between the electrodes is a good indicator of system health. Some care must be taken in collecting this measurement, as the sensor will also be powered from the cell it is measuring. For this application, however, an isolated differential ADC is sufficient to capture the needed measurements.

As envisioned, there is not significant need for on-board processing in our design. One might imagine performing the anode health check fully locally and only sending events when it is failing. However, part of the goal of this monitoring system is active confirmation that cathodic protection is still functioning as intended. If messages are sent too infrequently, is it because the local control loop believes everything is working or becuase there has been an unexpected sensor failure? For simplicity, we elect to simply send every measurement as it is collected in our prototype design. For processing, this means that largely any low-power microcontroller with a differential ADC will support our desired application.

4.3.1 Would Measuring Current Help? Measuring current does not provide meaningful additional information about the health of the anode. Instantaneous current informs the instantaneous rate of corrosion. This is not a good parameter to measure overall health of cathodic protection, however, as it is affected by various environmental factors such as the concentration of anode ions in the solution(s), the formation of passivisation layer(s) on the cathode in case of certain metals, stray currents, and the overall resistance of the electrolyte. For cathodic protection, the salient question is whether there is enough EMF to prevent the undesired corrosion reaction. As accurate current measurement is more challenging than potential, and the application of current data is less immediately clear, we omit current measurement from the sensor design.

Design Implication: Sensing events are short, atomic operations with a deterministic, fixed energy cost.

\subsection{Communication}

The final element of the system is a means to communicate back the sensed data on cathodic protection performance. Historically, communications have required low-power sensing systems to deploy 802.15.4 gateways, or more recently Bluetooth Low Energy gateways, near sensing devices. As these cathodic protection sensors are imagined pervasively in the built environment, beginning with approximately one per household when considering home hot water heaters, a real-world deployment using these technologies would likely require deploying a gateway for every sensor as well.

Recent LPWAN technologies, however, promise wide-area coverage of urban and peri-urban spaces without requiring local gateways for each sensor. To that end, we are excited to report that the promises of LPWAN technology are real. Indeed, commercial LoRa infrastructure is already deployed at scale and working in realworld cities today. We deploy no gateways or infrastructure for this project, yet are able to recover data transmitted from the authors' homes using commercially available LoRaWAN infrastructure.

LoRa radios are more energy-intensive than 802.15.4 or BLE radios, however. They also provide a much wider tradeoff space between energy and performance than most traditional radios. Of particular interest to energy-harvesting designs, which are sensitive to peak voltage, the Murata LPWAN module (CMWX1ZZABZ-078) allows users to vary the core voltage of the module. The tradeoff is that peak transmisson power is only available in higher voltage modes. As we aim to maximize the deployability of the system, to maximize the chance of the signal exiting a home and successfully reaching an extant LoRa gateway, we design for the highest transmission power, despite the modest increase in energy demand.

In addition to being more energy-intensive than BLE or 802.15.4, LoRa performance may also be less deterministic (a property we explore empirically in Section 6.6). Before a node can transmit data, it must first join a LoRaWAN network. Once joined, data transmission is stochastic, which may result in a collisions and requisite re-transmission (with growing likelihood as the number of deployed devices grows [14]). For reliable transmissions, LoRa includes an acknowledgement channel, but the protocol design only sends acknowledgements at one and two second intervals after data transmission. A design that wishes to support a modest number of re-transmissions (when needed) must therefore over-provision for comparatively long-term operation.

Design Implication: Communication events will have an energy requirement drawn from a distribution, thus there will be a tradeoff between energy buffer size and communication reliability.

\subsection{Execution Model}

From our experimentation in Section 3, the instantaneous power available can be very limited. Thus, we will need to adopt an energy harvesting architecture. In contrast to many prior energy harvesting designs, however, ambient galvanic cells enable a new, more reliable execution model that we term deterministic intermittent operation.

Ambient galvanic cells operate differently than more common energy scavenging sources such as solar, RF, or thermal. These sources can come and go unpredictably, which requires systems to time-shift energy accumulation, execution, or both. Even with advanced techniques, prior work has shown that when the underlying energy source is intermittent achieving reliable operation requires non-renewable, permanent backing stores (batteries) [19].

While the power available from an ambient galvanic cell is limited, it is not intermittent. Systems can design around constant, predictable energy income. This means that the decision to use an RTC for timekeeping introduces no burden or complexity on the power system, since the RTC power draw is well below that of the continuous power delivery capability of the proposed cell. Beyond timekeeping, system operation will still be intermittent, as the limited energy income must be buffered to enable higher-power activities. As the income is predictable, however, end devices can provide strong guarantees to systems, i.e. that a measurement will be sent every day, despite their intermittent operation. The predictable energy income afforded by ambient galvanic cells is the key to enabling deterministic intermittent operation. 
Table 2: System Configuration Options. The performance and ability of the LoRa radio vary based on supply voltage. The MCU also allows a range of supply voltage options. Voltage configuration selection affects both the peak power demand and longitudinal energy use of the system. To estimate energy use, we imagine one sense and send event per day. The energy per $24 \mathrm{~h}$ figure includes RTC usage and an approximation of startup and shutdown timing for the microcontroller and radio. The most significant differences come from the transmit power configuration of the LoRa radio.

\begin{tabular}{ccccc|c}
$\begin{array}{c}\text { MCU } \\
\text { voltage }(\mathrm{V})\end{array}$ & $\begin{array}{c}\text { MCU peak } \\
\text { current }(\mu \mathrm{A})\end{array}$ & $\begin{array}{c}\text { Transmission } \\
\text { Power }(\mathrm{dBm})\end{array}$ & $\begin{array}{c}\text { LoRa } \\
\text { voltage }(\mathrm{V})\end{array}$ & $\begin{array}{c}\text { LoRa peak } \\
\text { current }(\mathrm{mA})\end{array}$ & $\begin{array}{c}\text { Energy } \\
\text { per } 24 \mathrm{~h}(\mathrm{~J})\end{array}$ \\
\hline 1.8 & 10 & 10 & 2.4 & 36 & 0.85 \\
3.3 & 6 & 10 & 2.4 & 36 & 1.07 \\
1.8 & 18.2 & 10 & 2.4 & 36 & 0.85 \\
3.3 & 10.3 & 10 & 2.4 & 36 & 1.07 \\
1.8 & 10 & 14 & 2.4 & 47 & 0.99 \\
3.3 & 6 & 14 & 2.4 & 47 & 1.20 \\
1.8 & 18.2 & 14 & 2.4 & 47 & 0.99 \\
3.3 & 10.3 & 14 & 2.4 & 47 & 1.20 \\
1.8 & 10 & 20 & 3.6 & 128 & 2.87 \\
3.3 & 6 & 20 & 3.6 & 128 & 3.09 \\
1.8 & 18.2 & 20 & 3.6 & 128 & 2.87 \\
3.3 & 10.3 & 20 & 3.6 & 128 & 3.09
\end{tabular}

Deterministic intermittent operation should be viewed differently from duty-cycled operation. In normal, steady-state operation, the execution pattern looks identical. However, traditional dutycycled systems employ a conventional battery that is designed for power delivery, which is capable of delivering power on-demand. This means that when new workloads (new firmware?) or exceptional situations arise, duty-cycled systems expect to be able to (temporarily, perhaps) adapt duty cycle. In contrast, while a deterministic intermittent system will not wake up less often than promised, it is also incapable of waking more often - even just once. We introduce this new term to highlight and capture this difference: deterministic intermittent operation is a hard, fixed duty cycle.

Design Implication: Ambient galvanic cells enable reliable, deterministic designs that do not rely on non-renewable batteries.

\subsection{Power Supply}

With all of the operational pieces in place, we now need to power our design. To support our deterministic intermittent execution model, the power subsystem must both buffer energy for senseand-send events and provide continuous trickle power for the RTC.

4.6.1 Energy Buffer. From each of the subsystems previously identified, we have constraints on system voltage and instantaneous current draw. Table 2 considers the performance tradeoff across the array of available transmission power, MCU voltage, and radio voltage options. In sum, the radio will accept voltages from $2.4-3.6 \mathrm{~V}$ and the chosen MCU ranges from 1.8-3.3 V. For an energy harvesting system with such ranges, one should consider the lessons from UFoP [16], and evaluate whether to select a singular system voltage or regulate each component independently. In this system, LoRa dominates energy demand. Because we send data on every wakeup and because of the comparatively stable energy supply available from the corrosion cell, the marginal energy savings of federated power banks is not worth the complexity for this design.
Table 3: Energy Harvester Comparison. We survey some of the recently available energy harvesters in the market to understand the trade off between the cold start and the conversion efficiency to select the appropriate harvester. The stable voltage output of corrosion allows the selection of a higher efficiency harvester.

\begin{tabular}{lcccrc} 
Part & $\begin{array}{c}\text { Cold } \\
\text { Start }(\mathrm{mV})\end{array}$ & $\begin{array}{c}\text { Minimum } \\
\text { Input }(\mathrm{mV})\end{array}$ & $\begin{array}{c}\text { Start-up } \\
\text { Power }(\mu \mathrm{W})\end{array}$ & $\begin{array}{c}\text { Output } \\
\text { Range }(\mathrm{V})\end{array}$ & $\begin{array}{c}\text { Eff. at } \\
1 \mathrm{~V}, 0.1 \mathrm{~mA}\end{array}$ \\
\hline LTC 3105 & 250 & 225 & 6 & $1.6-5.25$ & 0.8 \\
LTC 3108 & 20 & 20 & 60 & $2.35-5$ & 0.2 \\
LTC 3109 & \pm 30 & \pm 30 & 180 & $2.35-5$ & 0.5 \\
ADP 5091 & 380 & 80 & 6 & $1.5-3.6$ & 0.9 \\
S6AE101A & 2000 & 2000 & 1.2 & $1.1-5.2$ & - \\
BQ2550 & 600 & 100 & 15 & $2-5.5$ & 0.8
\end{tabular}

We next need to estimate the required charge, discharge, and storage capacity of the energy storage element. To do this, we project from our component selection and system architecture the energy needs of our proposed sensing system. Over the course of a sense and send event, we expect to wake, sample the ADC, join a LoRa network, and send data. In practice, the energy demands from LoRa so dominate the system that we can focus on just that component. In the worst case, a LoRa transmission takes around $2.5 \mathrm{~s}$ [14]. At the highest power radio transmission, each event will conservatively require around $3.6 \mathrm{~V} \times 128 \mathrm{~mA} \times 2.5 \mathrm{~s}=1.1 \mathrm{~J}$. In addition, the power supply must be able to satisfy the relatively high $128 \mathrm{~mA}$ peak current draw of the LoRa radio.

We choose a supercapacitor for energy storage. Rechargeable batteries are not well-suited as they have limited charge cycles, tend to support only one of trickle charging or high peak current draw, and may not be able to charge to our required 3.6 V. Capacitors and supercapacitors allow wide voltage ranges, effectively unlimited charge cycles, and wide dynamic range input and output currents. As the energy demand of the LoRa radio is high, we elect to use a supercapacitor for its improved energy density compared to the tantalum capacitors often employed in energy harvesting designs.

4.6.2 Harvesting. Finally, we survey energy harvesting ICs, summarized in Table 3, to understand available tradeoffs. Energy harvesters that can cold-start from low voltages tend to have worse efficiency when operated with higher inputs. While our corrosion cell may have limited current, its nominal voltage is around $1.1 \mathrm{~V}$. More importantly, NACE guidelines state that effective cathodic protection requires several hundred millivolts (depending on deployment conditions). This higher voltage floor allows for the selection of a more efficient harvester with a higher minimum voltage.

\section{IMPLEMENTATION}

To test the energy harvesting corrosion monitor proposed in this paper, we build a prototype implementation of the sensing system described in the previous section. Following the hardware surveys, we select the lowest-power and most efficient components. Specifically we use an AM08x5 RTC for its lowest-energy timing, an Ambiq Apollo3 (on a SparkFun Artermis Red Board) for its mixture of low power operation, quick entry and exit from sleep, quality differential ADC, and ease of use, an STM32 B-L072Z-LRWAN1 Discovery Board LoRaWAN module for flexible communications, 


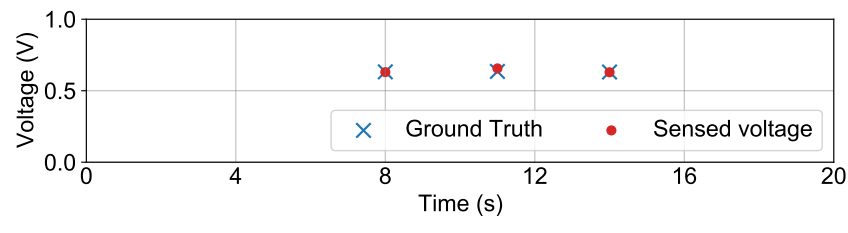

Figure 9: End-to-end Data. In-situ measurement data of corrosion cell potential (EMF) collected via our measurement system. The system is able to wake, charge, sample, and send measurements of cathodic protection using energy harvested from the cathodic protection system itself. The EMF reported by the sensor matches ground truth EMF measurements, which demonstrates the effectiveness of the sensing system.

a $0.5 \mathrm{~F}$ supercapacitor for energy storage, and an ADP5091 for efficient energy harvesting. The chosen harvester can boost up to $3.74 \mathrm{~V}$. To ensure ample energy for sense and send events, we configure the harvester to charge the supercapacitor fully to $3.74 \mathrm{~V}$ before the system is powered on.

\subsection{Data and Implementation Artifacts}

All data and source material from this work will be made publicly available (via Github) after anonymous review.

\section{EVALUATION}

Our evaluation is made up of three major stages. First, we seek to answer the question: does it work? We develop a lab-friendly hot water tank and then deploy our energy-harvesting monitoring sensor. We are able to demonstrate end-to-end delivery of anode health data over LoRa. Next, we investigate the utility of the monitor as a tool for detecting the failure of cathodic protection. We accelerate the deterioration of a sacrificial anode and demonstrate that the monitoring system can detect and report as the cathodic protection approaches and crosses failure thresholds. Finally, we explore some system microbenchmarks. Unless otherwise noted, all measurements are collected from a RocketLogger [33].

\subsection{Experimental Setup}

For experimental purposes, hot water tanks are slightly challenging, as a brand new tank should not actually need any cathodic protection. While the exterior is metal, hot water tank interiors feature a glass lining, which is a coating that acts as the first line of defense against corrosion. Thus a tank (ideally) begins its service life electrochemically inert. While this lining will eventually break down over time, we seek out a more reproducible system to test on.

In addition the tank itself, electric water heaters have a second source of potential corrosion. The heating element is necessarily immersed in the water. Generally, these elements are made out of some form of stainless steel in an effort to lessen corrosion (the material-selection defense), but cathodic protection is still necessary to prevent wear. For our home hot water heater experimentation, we focus on the corrosion of the electric heating element.

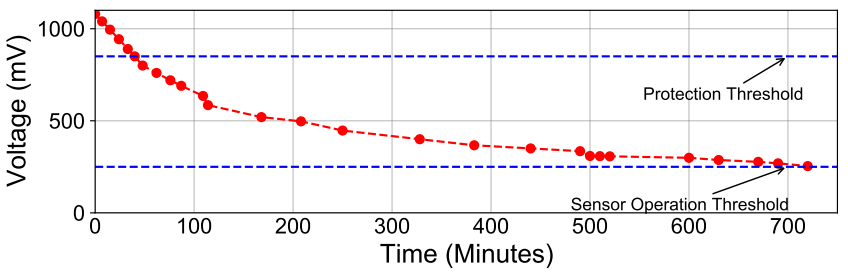

Figure 10: Cathodic Protection Failure. We replace the magnesium rod with a small strip designed to fail. Over a period of time the electrode potential drops substantially from $1.08 \mathrm{~V}$ to $0.25 \mathrm{~V}$ over a period of 12 hours. The minimum voltage required for the energy harvester cold start is $0.38 \mathrm{~V}$ and thus once the electrode potential drops below this value the system will stop working and no transmission of packets will take place.

\subsection{End-to-End Test}

In Fig. 9, we can see data recovered via LoRa that was collected from the sensor monitoring the health of the heater cathodic protection system. At time 0 , the supercapacitor finishes charging and the system is powered on. After several seconds, it successfully authenticates to the LoRaWAN network. The system then begins sending data packets as quickly as the LoRa radio will allow, successfully sending three packets before running out of stored energy.

\subsection{Cathodic Protection Failure}

The purpose of the monitoring system is to detect and alert when cathodic protection fails or will soon fail. As discussed earlier the capability of the cathodic protection system is directly related to the potential difference between the electrodes. Failure of the cathodic protection can be thus termed as the loss of potential difference between the electrodes. While the surface area experiment in Fig. 4 effectively demonstrates behavior when there is too little anode in the electrolyte, it is not representative of real-world failure. However, even under artificially advanced corrosion conditions (high temperature, high salinity, and low $\mathrm{pH}$ ), it would take weeks for our hot water tank to corrode our magnesium rod.

To induce premature failure, we replace the full-size rod with magnesium tests strips. We use a $62.5 \times 18 \times 1.2 \mathrm{~mm}$ strip of magnesium, which is approximately $2.35 \mathrm{~g}$ and thus sufficient for $2.8 \mathrm{Ah}$ of protection. We place this strip in a solution with a high concentration of salt to accelerate its corrosion. Figure 10 shows the result of this deliberate protection failure. Even as the protection falls below the $850 \mathrm{mV}$ threshold, our sensor is able to continue operating and to report the progression of the protection failure. Eventually, the failure is so acute that the cell potential falls below the minimum required by the energy harvesting frontend, at which point the sensor ceases operation.

\subsection{Energy Harvesting and Use}

As our hot water tank equipment is new, most of the initial (i.e. material, coating) corrosion protection is still at its most effective. As a result, the available charging current is about $10-15 \mu \mathrm{A}$. For a $0.5 \mathrm{~F}$ load it takes about three hours to charge to $3.74 \mathrm{~V}$. Figure 11 looks at how this energy is spent over the duration of one sense and send event. The average power draw over the entire duration is 

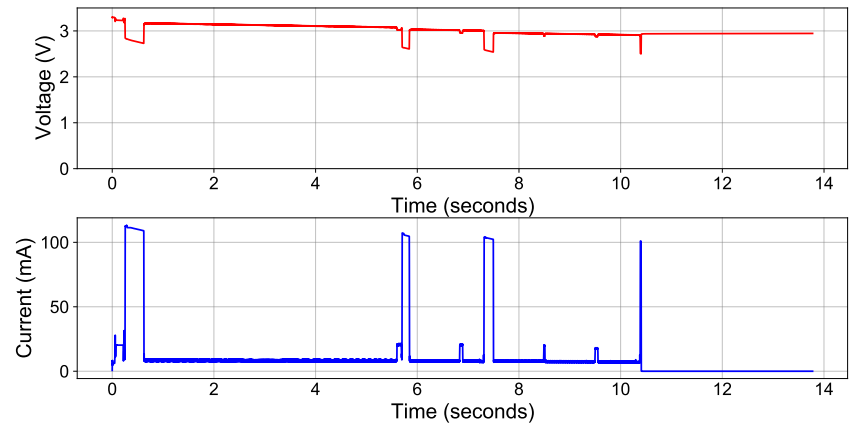

Figure 11: Energy Trace. We monitor the storage capacitor and the current draw of the system during a sense and send event. The first long peak corresponds to sending the OTAA (authentication) packet to join the LoRaWAN Network. Next, at around $6 \mathrm{~s}$, we see the reception of the downlink message that confirms the network has been joined successfully. This is followed almost immediately by the transmission of a data packet, which is acknowledged one second later. Then, there is a data packet where the first acknowledgment is missed, but the second is received. Finally, the attempt at sending a third data packet is cut short when the system powers off. The current required for each transmission is high, which causes the supercapacitor voltage to droop. Once the voltage dips below $2.5 \mathrm{~V}$, the harvester powers off the system.

about $30.7 \mathrm{~mW}$, for an overall energy consumption around $460 \mathrm{~mJ}$. This is well under the worst case predicted energy consumption of $1.1 \mathrm{~J}$ from Section 4. The energy headroom added for LoRa uncertainty allows a few additional packets when the network has minimal latency. Qualitatively, the system can usually send three packets with the current energy buffer configuration. In the trace in Fig. 11, however, the first acknowledgement from the second packet was missed, and the ensuing delay left insufficient energy to finish transmitting the third packet.

\subsection{A Natural Experiment on COTS LoRa}

As system builders, one of the most exciting and surprising aspects of this project was not needing to deploy any communications infrastructure. Deploying our own LoRa gateways was the initial plan. However, the closing of campus labs and confinement to homes during SARS-CoV-2 created a natural experiment. Suddenly, we had LoRa radios in our homes, but no chance to deploy our own infrastructure around the city-exactly what our long-term application design had imagined. Remarkably, by simply configuring our radios to join the Helium network [15], a commercial LoRa deployment, we were able to recover our data with standard cloud services. With no planning, for two locations nearly $15 \mathrm{~km}$ apart in a larger US city, ambient LoRa "just worked."

We include this anecdote as we believe it to be a somewhat remarkable and valuable case study. Communications infrastructure has long been one of the leading impediments for real-world deployment of sensors to monitor the built environment. This experience suggests that this may no longer be the case, and that the blanket connectivity enjoyed by high-power cellular-based platforms may now be available to low-power, energy-harvesting systems as well.

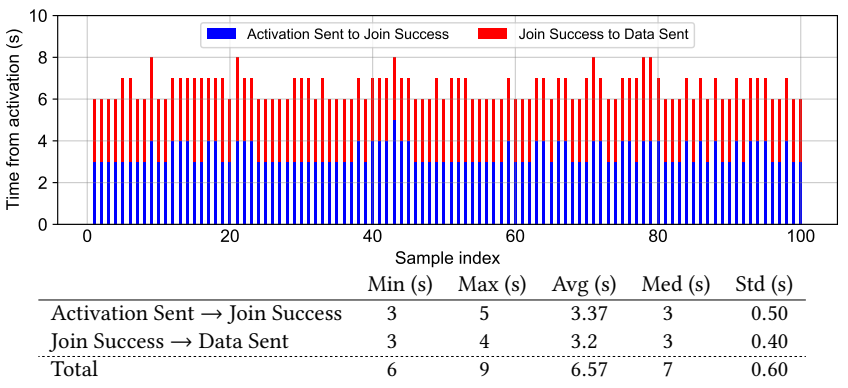

(a) Latency measured from the LoRaWAN cloud console.

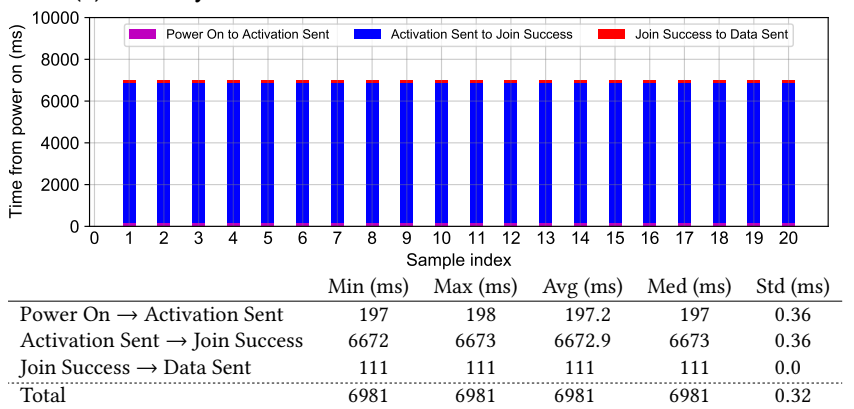

(b) Latency as measured from the sensor.

Figure 12: Latency to join the LoRa network. When observing a large number of events, we observe non-trivial jitter in the time required to join and transmit data seen from the perspective of the LoRa console in the cloud (a). As such non-deterministic delays could have significant impact on the requisite energy buffer, we collect the same data measuring when events occur on the end device (b). On the edge device, we find minimal jitter, as expected. We attribute the jitter seen in the cloud console to limited measurement resolution and network delays unrelated to the LoRa link.

\subsection{Latency and Jitter with COTS LoRa}

As an energy-scavenging system with a fixed energy buffer, it is important that events occur within the energy allotted to them. ${ }^{9}$ While a full evaluation of the available COTS LoRa network is outside the scope of this paper, in Fig. 12 we look at the timing required to wake, connect, and transmit a single data packet. Before data can be sent, devices must first send a message to "activate" which results in a reply from the network that has been "join"ed when complete-this establishes the LoRa session key (among other things). Figure 12 shows the timing of these events, first as presented by the developer console of the LoRaWAN cloud and then as measured by the end device. The cloud console reported non-trivial jitter in the timing of these events, which could have significant implications on the requisite energy buffer for our sensor. To understand the impact on the end device then, we next measured the latencies of stage on the sensor node, where we find almost no variation. We attribute the jitter seen in the cloud console to network and cloud processing delays unrelated to the LoRa connection.

${ }^{9}$ Indeed, this is why we consider a full OTAA handshake every time throughout this LoRa analysis. While session keys can be cached, they must occasionally be renegotiated, and the edge device must have sufficient energy to do so. 


\section{DISCUSSION}

Corrosion is a complex, multi-faceted topic. With this system, we have shown how cathodic protection can be leveraged as a reliable, ambient energy source for sensor applications. We have also shown how sensing can help enhance the reliability of corrosion control systems. In closing, we look first at unresolved questions and future potential for corrosion monitoring. We then step back and look at the broader potential for ambient galvanic cells, a new energy source pervasively available in the built environment.

\subsection{Potential Confounds of Health Estimation}

In many ways, hot water heaters simplify estimating cathodic protection health. Most importantly, they provide a predictable environment, which removes confounding variables that a monitoring system may otherwise need to capture and correct for. Tanks are likely indoors and by definition keep the galvanic cell at a reasonably stable (if hot) temperature. The electrolyte is also mostly consistent over time. While there may be variation between tanks (e.g. hard or soft water; municipal or well water), the electrolyte in one specific cell is unlikely to change dramatically. We can further assume that the water can be considered fresh and stationary. If it is stagnant, a concentration of corrosion product can build up and slow the reaction. Additionally, turbulent or laminar flow across electrodes can significantly affect cell performance. Thus, we assume there is no flow when we sample. In a home setting, these are reasonable assumptions, but in other environments, these additional factors may need to also be accounted for.

\subsection{Other Cathodic Protection Systems}

The built environment is full of cathodic protection. However, the accessibility and performance of an ambient galvanic cell may depend on its deployment conditions. Figure 13 shows two examples of other widespread corrosion cells, a water main and a concrete structure. In hot water heaters, the anode and cathode are readily exposed. In these cells, deployment would require either digging up soil or construction-time connection. Furthermore, the electrolyte in these cells will vary more dramatically, both in baseline performance and possibly over time. For the water main, depending on composition and moisture content, the electrical conductivity of soil ranges from $0.04-8 \mathrm{dS} / \mathrm{m}$ [21]. Similarly, depending on the composition, curing (drying) conditions, and other factors, the resistivity of concrete can range from $100 \Omega / \mathrm{m}$ to $10 \mathrm{M} \Omega / \mathrm{m}$ [10]. The takeaway here is that while ambient galvanic cells share underlying operational principles, their performance can still be highly deployment-dependent, and there is rich opportunity for future work to characterize the breadth of harvesting opportunity and system design points across these varied ambient energy sources.

\subsection{Impressed Current}

In addition to the galvanic approach discussed in this paper, the other primary form of cathodic protection is impressed current. Impressed current is an active system that uses a DC power source to continually force charge onto a protected structure. In principle, interposing on an impressed current system would allow a sensor mains-like power, since the power source will increase energy delivery to match perceived losses in the system. We see this as

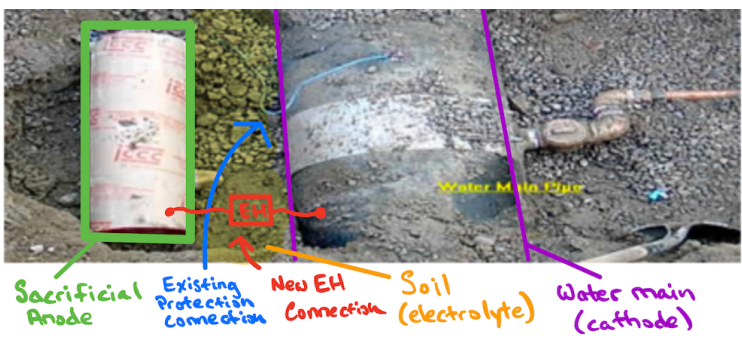

(a) Water main deployment. (Graphic adapted from [20])

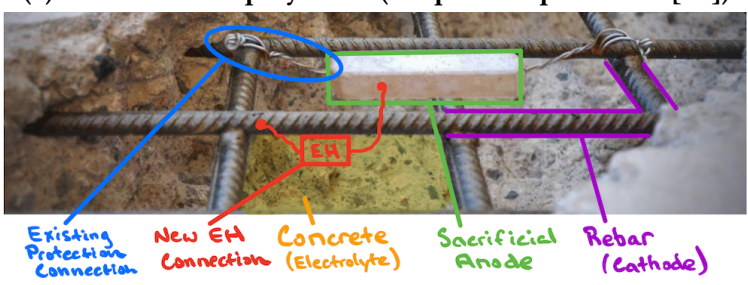

(b) In-concrete deployment. (Graphic adapted from [39])

Figure 13: Other Galvanic Cathodic Protection in the Wild. "Corrosion batteries" are surprisingly ubiquitous structures, integrated into much of the built environment. By creating a new connection between the sacrificial anode and the protected structure, we can siphon off sufficient energy to intermittently power a sensor, without interfering with the primary corrosion protection task. To help demonstrate the availability beyond the hot water tank scenario discussed in this paper, we label the principle components in two other deployment scenarios and identify where an energy harvesting unit could be deployed to capitalize on these sources.

a potentially interesting avenue to explore in future work, but note that impressed current systems are expensive to install and maintain and therefore typically see use only in more specialized systems - they are not ubiquitous in the same way as the passive galvanic protection studied in this work. Indeed, as part of defense in depth against corrosion, many impressed current designs also include galvanic cathodic protection as a backup system and as a method to protect hard-to-reach areas.

\subsection{Ambient Batteries}

This paper uses ambient cathodic protection systems to measure the health of ambient cathodic protection systems. While this is a valuable demonstration application for the efficacy of this energy source, we see the true potential of this work as the opening of a new line of energy scavenging opportunities. Cathodic protection systems exist in dark, RF-unfriendly, temperature-controlled machine rooms. They can be found buried underground or embedded into buildings. They are an energy source for general-purpose sensing applications available where traditional energy harvesting may not be viable. Furthermore, unlike most energy scavenging opportunities, in many cases their power potential is not intermittent, but fixed and deterministic, which greatly simplifies system design. We imagine a future with a wide array of systems deployed atop the power already available from the extant built infrastructure. 


\subsection{Related Work}

The state-of-the-art for monitoring galvanic cathodic protection systems today is manual inspection [35]. There have been some explorations into long-lifetime sensing to monitor large-scale infrastructure, primarily via RFID [2]. One particularly innovative design loads the RFID antenna with the rebar in concrete such that corrosion deterministically detunes the antenna [25]. The common thread among all existing corrosion measurement systems, however, is the requirement of in-person visitation, whereas our system enables remote monitoring of galvanic protection systems.

The notion of corrosion as a battery-like structure is surprisingly common. Indeed, chemistry textbooks [11] and corrosion handbooks [31] both introduce corrosion reactions are 'similar to those of a battery.' However, despite this prevalent analogy, we could not find any prior systems actually using real-world corrosion as a battery. We suspect that the limited instantaneous current available from corrosion cells, which requires our novel use of energy harvesting techniques to make practical for use with modern electronics, has inhibited prior exploration into "corrosion batteries."

\section{CONCLUSIONS}

The majority of infrastructure is relatively stable. It does not change quickly, but it does wear over time, which requires periodic monitoring and maintenance. The lifetime of this infrastructure is also often measured in decades-indeed, some bridges and pipelines predate transistors, let alone low-power sensing hardware. We show that today it is possible to tie the health of a sensing system to the health of infrastructure itself, which opens the door to sensors with decade-plus deployment lifetimes. The key insight is that the slow degradation of infrastructure is itself an energy source, albeit a very weak one. Because measurement events are rare, energy harvesters can integrate over very long windows, which allows for reliable operation even when scavenging from much less capable power sources. In conjunction with newly pervasive commercial LPWAN infrastructure, the two most significant historical impediments to real-world deployments-energy and communication-need no longer stand in the way of wide-area, ambient, microhertz sensing.

\section{REFERENCES}

[1] Citation blinded for anonymous review.

[2] M. Alhaideri, M. Rushanan, D. F. Kune, and K. Fu. The Moo and cement shoes: Future directions of a practical sense-control-actuate application. In First International Workshop on the Swarm at the Edge of the Cloud (at ESWeek), 2013.

[3] ASTM G 82 - 98 Standard. Technical report, 2013.

[4] ASTM G46-94(2018): Standard guide for examination and evaluation of pitting corrosion. Technical report, ASTM International, 2018.

[5] M. M. Benjamin, J. F. Ferguson, O. von Franqué, G. J. Kirmeyer, P. Leroy, R. J. Oliphant, S. H. Reiber, R. A. Ryder, M. R. Schock, V. L. Snoeyink, H. Sontheimer, R. R. Trussell, E. A. Vik, and I. Wagner. Internal Corrosion of Water Distribution Systems, 2nd Edition. American Water Works Association Research Foundation, June 1996.

[6] H. Davy. On the corrosion of copper-sheeting by sea-water, and on methods of preventing this effect; and on their application to ships of war and other ships. Abstracts of the Papers Printed in the Philosophical Transactions of the Royal Society of London, 2:207-207, 1833.

[7] J. de Winkel, C. Delle Donne, K. S. Yildirim, P. Pawełczak, and J. Hester. Reliable timekeeping for intermittent computing. In Proceedings of the Twenty-Fifth International Conference on Architectural Support for Programming Languages and Operating Systems, ASPLOS '20, 2020.

[8] Department of Defense, United States of America. Unified facilities criteria (ufc) operation and maintenance: Cathodic protection systems. https://www.wbdg.org/ FFC/DOD/UFC/ufc_3_570_06_2019.pdf, July 2019. UFC 3-570-06.
[9] DNV GL. Rp-b401 cathodic protection design. https://oilgas.standards.dnvgl.com/ download/dnvgl-rp-b401-cathodic-protection-design. Accessed 2020.

[10] W. Elkey and E. J. Sellevold. Electrical resistivity of concrete. 1995.

[11] K. Escobar and L. A. Cantu. Corrosion Basics. chem.libretexts.org/@go/page/255, 2020. Last Updated: Aug 15, 2020.

[12] E. J. Fasullo. Infrastructure: The Battlefield of Corrosion. Corrosion Forms and Control for Infrastructure. ASTM International, Jan 1992

[13] R. R. Fessler. Pipeline corrosion - Final report. Technical report, United States Department of Transportation, November 2008

[14] B. Ghena, J. Adkins, L. Shangguan, K. Jamieson, P. Levis, and P. Dutta. Challenge: Unlicensed LPWANs are not yet the path to ubiquitous connectivity. In Proceedings of the 25th Annual International Conference on Mobile Computing and Networking, MobiCom'19, 2019.

[15] Helium. The people's network. https://www.helium.com/. Accessed 2020.

[16] J. Hester, L. Sitanayah, and J. Sorber. Tragedy of the Coulombs: Federating energy storage for tiny, intermittently-powered sensors. SenSys '15, 2015.

[17] J. Hester and J. Sorber. The future of sensing is batteryless, intermittent, and awesome. SenSys '17, 2017.

[18] J. Hester, K. Storer, and J. Sorber. Timely execution on intermittently powered batteryless sensors. SenSys '17, 2017.

[19] N. Jackson, J. Adkins, and P. Dutta. Capacity over capacitance for reliable energy harvesting sensors. In The 18th International Conference on Information Processing in Sensor Networks, IPSN'19. ACM, April 2019

[20] Kentucky Department for Environmental Protection. Cathodic protection in a distribution system. https://kyocp.wordpress.com/2012/10/17/cathodic-protectionin-a-distribution-system/, 2012. Accessed 2020.

[21] F. Kizito, C. Campbell, G. Campbell, D. Cobos, B. Teare, B. Carter, and J. Hopmans. Frequency, electrical conductivity and temperature analysis of a low-cost capacitance soil moisture sensor. Fournal of Hydrology, 352(3-4):367-378, 2008.

[22] G. H. Koch, M. P. Brongers, N. G. Thompson, Y. P. Virmani, and J. H. Payer. Corrosion cost and preventive strategies in the United States. Technical report, United States. Federal Highway Administration, 2002.

[23] T. Li and X. Zhou. Battery-free eye tracker on glasses. MobiCom '18, 2018.

[24] A. Y. Majid, P. Schilder, and K. Langendoen. Continuous sensing on intermittent power. IPSN'20, 2020.

[25] N. Materer, A. Apblett, and T. Ley. Passive, wireless corrosion sensors for transportation infrastructure. Technical report, Oklahoma State University. Dept. of Chemistry, Jul 2011. OTCREOS7.1-34-F.

[26] Y. Matsukawa, H. Chuta, M. Miyashita, M. Yoshikawa, Y. Miyata, and S. Asakura. Galvanic series of metals conventionally used in tap water with and without flow and its comparison to that in seawater. CORROSION, 67(12), 2011.

[27] R. E. Melchers. 4 - Corrosion wastage in aged structures. In J. Paik and R. Melchers, editors, Condition Assessment of Aged Structures, Woodhead Publishing Series in Civil and Structural Engineering, pages 77 - 106. Woodhead Publishing, 2008.

[28] NACE International. NACE Standard RP0285-2002: Corrosion control of underground storage tank systems by cathodic protection. Technical report, 2002.

[29] nexperia. Leakage of small-signal MOSFETs. Technical report, 2019.

[30] G. E. Ragan, C. J. Makala, and R. A. Young. Improved estimates of economic damages from residential use of mineralized water. Completion report (Colorado Water Resources Research Institute); no. 183, 1993.

[31] P. R. Roberge. Corrosion Basics: An Introduction. NACE Press Book, 2006.

[32] G. Schmitt et al. Global needs for knowledge dissemination, research, and development in materials deterioration and corrosion control. Technical report, The World Corrosion Organization, May 2009.

[33] L. Sigrist, A. Gomez, R. Lim, S. Lippuner, M. Leubin, and L. Thiele. Measurement and validation of energy harvesting IoT devices. DATE'17, Mar 2017.

[34] State of Michigan: Department of Environmental Quality. Cathodic protection testing criteria. https://www.michigan.gov/documents/deq/deq-std-opmemo18_ 250026_7.pdf, January 2001. Accessed July 2020

[35] Transportation Research Board and National Academies of Sciences, Engineering, and Medicine. Cathodic Protection for Life Extension of Existing Reinforced Concrete Bridge Elements. The National Academies Press, Washington, DC, 2009.

[36] Use of cathodic protection of buried and submerged metals in corrosion prevention in electric power systems. Technical report, United States Bureau of Reclamation - Facilities Instructions, Standards, \& Techniques, 1992.

[37] United States Environmental Protection Agency. \$280.31 - Operation and maintenance of corrosion protection. https://www.ecfr.gov/cgi-bin/ text-idx?SID =51c36f5cac46e $18 f 5 \mathrm{c} 8 \mathrm{~d} 9030 \mathrm{~d} 61 \mathrm{ea} 0 \mathrm{e} 2 \& \mathrm{pitd}=20160601 \&$ node $=\mathrm{se} 40$. 27.280 131\&rgn=div8, June 2016. In Effect: June 1, 2016.

[38] United States Geological Survey (USGS). Saline water and salinity. https://www.usgs.gov/special-topic/water-science-school/science/salinewater-and-salinity. Accessed 2020.

[39] Vector Corrosion Technologies. Cathodic protection \& concrete corrosion protection. https://www.vector-corrosion.com/blog/cathodic-protection-concretecorrosion-prevention, 2020. Accessed 2020. 